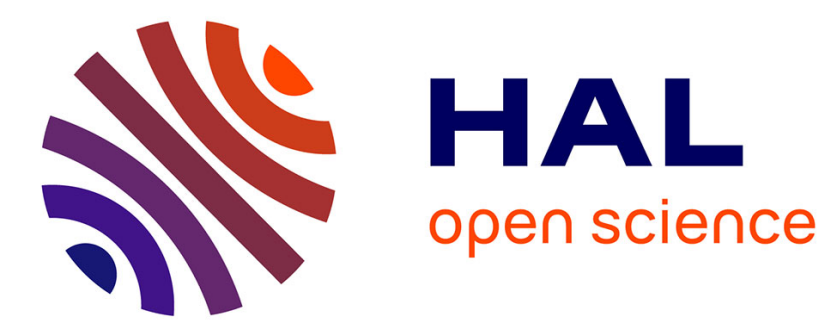

\title{
External dacryocystorhinostomy for the treatment of epiphora in patients with patent but non-functioning lacrimal systems
}

\author{
Neena Peter, Andrew Pearson
}

\section{- To cite this version:}

Neena Peter, Andrew Pearson. External dacryocystorhinostomy for the treatment of epiphora in patients with patent but non-functioning lacrimal systems. British Journal of Ophthalmology, 2010, 94 (2), pp.233-n/a. 10.1136/bjo.2008.152157 . hal-00508657

\section{HAL Id: hal-00508657 \\ https://hal.science/hal-00508657}

Submitted on 5 Aug 2010

HAL is a multi-disciplinary open access archive for the deposit and dissemination of scientific research documents, whether they are published or not. The documents may come from teaching and research institutions in France or abroad, or from public or private research centers.
L'archive ouverte pluridisciplinaire HAL, est destinée au dépôt et à la diffusion de documents scientifiques de niveau recherche, publiés ou non, émanant des établissements d'enseignement et de recherche français ou étrangers, des laboratoires publics ou privés. 
TITLE: External dacryocystorhinostomy for the treatment of epiphora in patients with patent but non-functioning lacrimal systems

$\begin{array}{ll}\text { AUTHORS : } & \text { Neena M Peter MA, MRCOphth }{ }^{1,2} \\ & \text { Andrew R Pearson MA, MRCP, FRCOphth }{ }^{1,2}\end{array}$

Institutions: ${ }^{1}$ Dept. of Ophthalmology, Royal Berkshire Hospital, Reading, UK

${ }^{2}$ Prince Charles Eye Unit, King Edward VII Hospital, Windsor, UK

\section{Corresponding Author}

NM Peter, Oxford Eye Hospital, The John Radcliffe, Headley Way, Headington, Oxford, OX3 9DU

E-mail: neenapeter@yahoo.co.uk

Tel:01183228739 Fax: 01753583712

Keywords: dacryocystorhinostomy, epiphora, functional obstruction

Word Count: 2104 


\section{ABSTRACT}

Aims: To assess the outcome of external dacryocystorhinostomies (DCRs) in patients with patent but non-functional lacrimal drainage systems and to identify any preoperative clinical or dacryocystography (DCG) and lacrimal scintigraphy (LS) factors associated with successful surgery.

Methods: A retrospective study of 46 DCRs with silicone intubation performed for patients with epiphora associated with a clinically patent lacrimal drainage system. All patients underwent pre-operative DCG and LS which were evaluated for presence, site and severity of delayed clearance. DCGs were also evaluated for reflux and anatomical abnormalities. Postoperative success was determined by subjective resolution of epiphora. Patients with persistent symptoms were offered Lester Jones Tube (LJT) insertion after establishment of a patent anastomosis to syringing and normal ostium on nasal endoscopy. Statistical analysis was performed using the Chisquare and Fisher's exact tests to determine whether there was any association between surgical outcome and pre-operative resistance to lacrimal syringing, DCG and LS findings.

Results: 29 cases (63\%) reported subjective surgical success after 11 months' average follow-up. There was a statistically significant association between increased resistance to syringing pre-operatively and successful DCR $(\mathrm{p}=0.012)$. Of the 17 eyes that failed, all had patent anastomoses, and 7 went on to have LJT insertion with complete resolution of symptoms.

Conclusion: The majority of patients with patent but non-functional lacrimal drainage systems will be helped by DCR surgery, with greater success rates in those with significant reflux on pre-operative syringing. For patients with residual epiphora functional success can reach $100 \%$ with subsequent LJT insertion. 


\section{INTRODUCTION}

External dacryocystorhinostomy (DCR) is established as an effective surgical treatment for complete nasolacrimal obstruction in adults, consistently yielding success rates in excess of $90 \% \cdot{ }^{1-6}$ However there is a significant subgroup of symptomatic patients without clinical evidence of pump failure where there is delayed drainage yet the lacrimal system on syringing is patent, who may also benefit from treatment. The outcome of DCR surgery in these challenging patients is less clear, with reported success rates ranging from $50-94 \% .^{7-9}$

The purpose of this study was to assess the outcome of external DCR in this group of patients with patent but non-functional lacrimal drainage systems and to identify any pre-operative clinical or dacryocystography (DCG) and lacrimal scintigraphy (LS) radiological factors associated with successful surgery.

\section{MATERIALS AND METHODS}

Data were collected retrospectively over a period of three years from patients undergoing external DCR surgery at the Royal Berkshire Hospital, Reading and King Edward VII Hospital, Windsor. Patients were included if they: had symptomatic or visible epiphora, had clinical evidence of delayed tear clearance (the fluorescein dye disappearance test, FDDT) without any externally visible cause, had undergone both DCG and LS investigations prior to their surgery, and had lacrimal systems that were patent on irrigation, i.e. $<100 \%$ regurgitation and passage of saline to the nose/throat detectable by the patient. The proportion of fluid regurgitating during irrigation was

quantified subjectively with $\leq 20 \%$ arbitrarily being taken as 'freely patent' and $>20 \%$ indicative of increased resistance. Exclusion criteria included patients with small or 
malpositioned puncti, a visible cause of impaired tear pump such as abnormal eyelid position, tone or movement, particularly eyelid laxity or impaired blink, any visible causes of hypersecretion, such as dry eyes, poor tear films, or ocular surface disease including significant blepharitis and any previous history of lacrimal surgery other than punctoplasty.

Our techniques of DCG, LS and lacrimal syringing have been described in detail elsewhere. ${ }^{10}$ All DCGs were evaluated for the presence of reflux from the canaliculi, abnormal anatomy, and delayed clearance and site of hold-up at 10 minutes, which was subjectively graded as none, mild, moderate or severe, with mild retention taken as normal. All scintigrams were evaluated for delayed transit, site of delay and severity, which was classified according to the time for the tracer to reach the nose: mild delay 6-15 min; moderate delay 16-30 min; severe delay 31-45 min; very severe delay >45 min. DCG and LS findings were assessed in a randomised, masked fashion by an experienced observer who was blinded to all clinical data. A subgroup of 15 DCGs and LSs (30 systems) were randomly selected to be re-assessed by the same author in order to evaluate intra-observer variation.

All patients underwent standard external DCR surgery under general anaesthetic, performed by a single experienced specialist oculoplastic surgeon. Surgery involved complete opening of the lacrimal sac, suturing of posterior and anterior flaps and placement of silicone O’Donoghue tubing.

Postoperative topical corticosteroid-antibiotic eyedrops were prescribed for 4 weeks. Tubes were routinely removed 2 weeks after surgery, unless there had been any 
intraoperative evidence of canalicular narrowing or a membranous obstruction at the sac entrance, in which case they were left in for 12 weeks. For those still symptomatic at 2 weeks the tubes were left for a further 4 weeks. Following removal of the silicone tubes, patients with no or minimal epiphora were classified as a successful outcome. Patients with significant persistent postoperative epiphora were investigated with the FDDT, lacrimal syringing of the anastomosis and nasal endoscopy for direct inspection of the size and position of the internal ostium, presence of adhesions, granulation tissue or sump formation. If no abnormality was found, i.e. DCR was patent but not functioning, with no definite cause for persistent symptoms, they were offered Lester Jones Tube (LJT) insertion. Those who proceeded were followed up for a minimum of 6 months.

All data was recorded and analysed with the software SPSS release version 9.0. Chisquare and Fisher's exact tests were used to assess whether there was any association between surgical outcome and pre-operative resistance to lacrimal syringing, DCG and LS findings, with a $\mathrm{p}$ value of $<0.05$ being considered statistically significant.

\section{RESULTS}

DCR surgery was performed on 50 lacrimal systems - one was excluded due to previous lacrimal surgery, and three were lost to follow-up. Thus a total of 46 procedures in 42 patients ( 25 males, 21 females ) were included in the study. The average age was 65 years with a range from 39 to 87 years. Four patients had bilateral sequential surgery, and the remaining 38 had unilateral DCRs. No major intraoperative or postoperative complications were observed. 11 eyes (24\%) had had previous surgery: 4 systems had undergone anatomically successful punctoplasty 
surgery for punctal stenosis and 6 patients ( 7 systems) had previously had anatomically successful lateral tarsal strip surgery for lower eyelid laxity. Removal of silicone tubes was performed at 2 weeks in 38 eyes (82\%), at 6 weeks in 4 eyes (9\%), and at 12 weeks in 4 eyes (9\%). The average length of post-operative follow-up was 11 months (median 6 months; range 2 weeks to 3 years).

\section{Pre-operative findings}

All baseline clinical and radiological characteristics are summarized in Table 1. Reassessment of the radiological investigations revealed no intra-observer variation.

Table 1: Pre-operative findings of 46 eyes

\begin{tabular}{|c|c|c|c|}
\hline FDDT & \multicolumn{2}{|c|}{ Delayed: 46} & Normal: 0 \\
\hline Lacrimal syringing & \multicolumn{2}{|c|}{$\begin{array}{l}\leq 20 \% \text { regurgitation: } 30(65 \%) \\
\text { ('freely patent') }\end{array}$} & $>20 \%$ regurgitation: 16 \\
\hline \multirow[t]{6}{*}{ DCG } & \multicolumn{2}{|c|}{ Normal: } & $9(20 \%)$ \\
\hline & \multicolumn{2}{|c|}{ Abnormal anatomy: } & $22(48 \%)$ \\
\hline & \multicolumn{2}{|l|}{ Reflux: } & $25(54 \%)$ \\
\hline & \multirow[t]{3}{*}{ Delay: } & & $24(52 \%)$ \\
\hline & & SITE & $\begin{array}{l}\text { Canalicular: } 2(4 \%) \\
\text { Sac: } 6(13 \%) \\
\text { Duct: } 16(35 \%)\end{array}$ \\
\hline & & SEVERITY & $\begin{array}{l}\text { Moderate: } 14(30 \%) \\
\text { Severe: } 10(22 \%)\end{array}$ \\
\hline \multirow[t]{3}{*}{$\mathbf{L S}$} & \multirow[t]{3}{*}{ Delay: } & & $46(100 \%)$ \\
\hline & & SITE & $\begin{array}{l}\text { Presac: } 5(11 \%) \\
\text { Sac: } 24(52 \%) \\
\text { Duct: } 17(37 \%)\end{array}$ \\
\hline & & SEVERITY & $\begin{array}{l}\text { Mild: } 10(22 \%) \\
\text { Moderate: } 10(22 \%) \\
\text { Severe: } 6(13 \%) \\
\text { V severe: } 20(43 \%)\end{array}$ \\
\hline
\end{tabular}




\section{Symptomatic outcome}

A successful outcome of no or minimal post-operative symptoms was achieved in 29/46 eyes (63\%). Surgery failed to improve symptoms in 17 eyes (37\%). There was no association between time for removal of silicone tubes and surgical outcome $(p=0.74)$

All patients with no improvement in symptoms or recurrence had poor tear clearance but patent systems on irrigation and 16 eyes had healthy DCR ostiums on endoscopy indicating that the DCR was non-functioning. One patient had initial success with the procedure, but represented a year later with recurrence, and was found to have a scarred ostium.

7/17 eyes that had failed had subsequent Lester Jones tube (LJT) insertion with complete resolution of symptoms - this was offered on average 6 months after the failed DCR (range 2 - 12 months). 10 patients declined any further interventions or are awaiting surgery.

\section{Lacrimal syringing and DCR success}

Surgical outcome of all patients was considered in terms of their degree of reflux on lacrimal syringing. There was a statistically significant association between increased resistance to syringing (>20\% regurgitation) pre-operatively and successful DCR with $88 \%$ success in those with increased resistance on syringing versus $50 \%$ of eyes with freely patent systems $(\mathrm{p}=0.012)$. 


\section{Radiological findings and DCR success}

A greater number of eyes with anatomical abnormalities on DCG had successful DCRs compared with those with normal anatomy (72\% vs 54\%), however the difference was not statistically significant $(\mathrm{p}=0.16)$. Similarly, a greater number of eyes with delayed clearance on DCG had successful DCRs compared with those with no delay ( $71 \%$ vs 55\%), however the difference was again not statistically significant $(\mathrm{p}=0.20)$. DCR was also more successful in systems with both abnormal anatomy and delay on DCG (76\% vs 55\%), however, the difference was not statistically significant $(\mathrm{p}=0.13)$. There was no association between presence of reflux on DCG and surgical success $(\mathrm{p}=0.33)$.

Our results did not show a statistically significant association between surgical success and site of delay on DCG ( $\mathrm{p}=0.41)$ or $\mathrm{LS}(\mathrm{p}=0.69)$, however the number of proximal obstructions was small in both groups. Similarly, there was no statistically significant difference between surgical success and the severity of delay on DCG $(\mathrm{p}=0.50)$ or $\operatorname{LS}(\mathrm{p}=0.31)$.

\section{DISCUSSION}

External DCR is a highly successful surgical treatment for epiphora caused by complete obstruction of the lacrimal duct, ${ }^{1,2}$ with success rates generally regarded as being in the order of $95 \%$ or higher. In contrast, its role in patients with epiphora from impaired outflow but patent drainage systems is less predictable. Recent reports in the literature have tried to evaluate the place of external DCR in the treatment of these challenging patients, however their results are inconsistent and their pre-operative assessments variable. O'Donnell et al. ${ }^{9,11}$ demonstrated a $94 \%$ success rate in 51 
patients and 68 patent systems that underwent external DCR after a short follow-up of 2 to 3 -months. However, $78 \%$ of their patients had significantly increased resistance to syringing, with $>50 \%$ reflux. Although all subjects had been evaluated using FDDT, lacrimal syringing and the Jones test, none had LS and DCG was used in only 12\%. Similarly, Delaney et al. ${ }^{7}$ reported an $84 \%$ success rate for 50 DCRs in freely patent systems after 3-4 months. All their patients had been assessed by the Jones test and LS prior to their surgery, though there was no DCG evaluation. In contrast, Sahlin and Rose noted only $50 \%$ overall success after 2 years in their retrospective cohort study of 22 eyes. Although the majority had undergone DCG none had had $\mathrm{LS}^{8}$

Our study is the first to report on the success of external DCR in patients with a clinically patent but non-functioning lacrimal drainage system diagnosed systematically with FDDT, lacrimal syringing, DCG and LS, with almost two thirds reporting significant improvement in symptoms. However, this success rate is considerably lower than for patients with complete $\mathrm{NLDO}^{6}$ (approaching $100 \%$ in a previous departmental audit and numerous published series). Our success rate is also lower than some other studies of this specific subgroup of patients.

There are several potential reasons for this difference. One explanation is the more stringent inclusion criteria used in this study - all of our patients had evidence of delay on FDDT, as well as demonstrating patency to syringing and lack of any anatomical obstruction on DCG. All subjects also had an abnormal LS - it has recently been demonstrated that LS is an extremely sensitive test in the evaluation of these patients, and correlates closely with the clinical examination. ${ }^{10}$ Previous reports 
have used the Jones test to assess function of the lacrimal drainage system in this group of patients, however this has been shown to have an error rate as high as $30 \%$ in patients with epiphora. ${ }^{12}$ While others have only used one or two methods of preoperative evaluation, ${ }^{8}$ we have used a variety of both clinical and radiological assessments to systematically diagnose a non-functioning but clinically patent lacrimal drainage system. A second possibility is the varying population groups included in other studies to date, such as large proportions of patients with significantly increased resistance to syringing associated with $>50 \%$ reflux. ${ }^{9,11}$ In contrast, the majority of our patients had $\leq 20 \%$ regurgitation on syringing. It is notable that patients with significant reflux on pre-operative syringing, indicating narrowing of the lacrimal passage from the sac to nose, had a more favourable surgical outcome. DCR surgery in these patients would be expected to improve flow of tears through the system and does indeed do so. In all cases, adequate movement of tears through the lacrimal system will be dependant on the balance between the forces that move tears through it and the resistance to flow. A third possibility is a decline of DCR success with time ${ }^{1}$ being revealed by our longer average follow-up compared to other published reports. ${ }^{8,9,11}$ Our data did not allow success rates to be analysed by a Kaplan-Meier plot, ${ }^{13}$ however our impression is that the success of surgery is usually apparent within a few weeks and later changes are very uncommon. In the approximately two thirds of patients with successful surgery physiological obstruction beyond the common canaliculus is strongly suggested as the cause of the failure to drain. What underlies the functional failure of drainage in the remaining $37 \%$ ? 
It is unlikely that the loss of the sac vacuum portion of the lacrimal tear pump following DCR surgery is responsible because this is affected equally whether the system beyond is completely or incompletely obstructed. Other possibilities include canalicular pump failure or undetected anatomical abnormalities such as canalicular narrowing or acute angulation at the junction with the lacrimal sac, or lack of an adequate Venturi effect across the nasal opening however, the explanation remains unknown. This poor correlation of objective surgical success and symptom improvement has also been reported following DCR for complete nasolacrimal duct obstruction, ${ }^{14,15}$ although the failure rates are much lower.

A limitation of this study is the retrospective design with the pre-operative assessment performed by several observers. However many of the sources of bias inherent to a study of this kind have been minimised: all operations were performed by a single experienced surgeon, who also assessed all radiologic findings in a blinded fashion.

In conclusion, our study demonstrates that the majority of patients with patent but non-functional lacrimal drainage systems will be helped by DCR surgery. For those with residual epiphora functional success can reach $100 \%$ with subsequent LJT insertion.

Competing interest: None declared

\section{Funding: None}


The Corresponding Author has the right to grant on behalf of all authors and does grant on behalf of all authors, an exclusive license (or non exclusive for government employees) on a worldwide basis to the BMJ Publishing Group Ltd to permit this article (if accepted) to be published in British Journal of Ophthalmology and any other BMJPGL products and sublicenses such use and exploit all subsidiary rights, as set out in our license (http://bjo.bmj.com/ifora/ licence.pdf).

\section{REFERENCES}

1 Tarbet KJ, Custer PL. External dacryocystorhinostomy. Surgical success, patient satisfaction, and economic cost. Ophthalmology 1995;102(7):1065-70.

2 Welham RA, Henderson PH. Results of dacryocystorhinostomy analysis of causes for failure. Trans Ophthalmol Soc UK 1973;93:601-9.

3 Hurwitz JJ, Rutherford S. Computerized survey of lacrimal surgery patients. Ophthalmology 1986;93(1):14-9.

4 Walland MJ, Rose GE. Factors affecting the success rate of open lacrimal surgery. Br J Ophthalmol. 1994;78(12):888-91.

5 Beigi B, Westlake W, Chang B, Marsh C, Jacob J, Chatfield J.

Dacryocystorhinostomy in south west England. Eye 1998;12( Pt 3a):358-62.

6 Zaman M, Babar TF, Saeed N. A review of 120 cases of dacryocystorhinostomies (Dupuy Dutemps and Bourguet technique). J Ayub Med Coll Abbottabad. 2003;15(4):10-2.

7 Delaney YM, Khooshabeh R. External dacryocystorhinostomy for the treatment of acquired partial nasolacrimal obstruction in adults. Br J Ophthalmol. 2002;86(5):5335. 
8 Sahlin S, Rose GE. Lacrimal drainage capacity and symptomatic improvement after dacryocystorhinostomy in adults presenting with patent lacrimal drainage systems. Orbit 2001;20(3):173-179.

9 O'Donnell B, Shah R. Dacryocystorhinostomy for epiphora in the presence of a patent lacrimal system. Clin Experiment Ophthalmol. 2001;29(1):27-9.

10 Peter NM, Pearson AR. Comparison of dacryocystography and lacrimal scintigraphy in the investigation of epiphora in patients with patent but nonfunctioning lacrimal systems. Ophthalmic Plast Reconstruct Surg. 2008 (in press). 11 O'Donnell BA, Clement CI. Assessing patients with epiphora who are patent to syringing: clinical predictors of response to dacryocystorhinostomy. Ophthal Plast Reconstr Surg. 2007;23(3):173-8.

12 Guzek JP, Ching AS, Hoang TA, Dure-Smith P, Llaurado JG, Yau DC, et al. Clinical and radiologic lacrimal testing in patients with epiphora. Ophthalmology 1997;104(11):1875-81.

13 Kaplan EL, Meier P. Nonparametric estimation from incomplete data. Journal of the American Statistical Association 1958;53: 457-481.

14 Cheung LM, Francis IC, Stapleton F, Wilcsek G. Symptom assessment in patients with functional and primary acquired nasolacrimal duct obstruction before and after successful dacryocystorhinostomy surgery: a prospective study. Br J Ophthalmol. 2007;91(12):1671-4.

15 Delaney YM, Khooshabeh R. Fluorescein transit test time and symptomatic outcomes after external dacryocystorhinostomy. Ophthal Plast Reconstr Surg. 2002;18(4):281-4. 